get things done, but always with an understanding of and respect for Indian ways and susceptibilities. Mr J. H. Burnett, who had known E.P. for 20 years, writes, 'the fact that India accepted him as a mentor and undisputed authority in anything connected with wildlife must surely be E.P.'s first testimonial'. His advice on wildlife was sought and respected by the government of Assam, by the national government of India and also in the neighbouring kingdom of Bhutan, where he had much to do with the setting up on the frontier of the Manas National Park contiguous with the Assam sanctuary of the same name (shortly to be declared a national park). These sanctuaries are the best memorial to E.P. and the only one he would have wanted.

The young Indian painter of the tigers was introduced to us by E. P. Gee.

\title{
The First Javan Rhino Calf
}

THE footprints of a Javan rhino calf only three to five months' old, together with those of a year-old rhino, were seen this year by Dr Rudolf and Dr Lotte Schenkel on their second visit to Udjung Kulon. This is most cheering news, as one of the disturbing facts about this last surviving population of the Javan rhino is that no calf had been seen for some years, and it was feared that the rhinos were not breeding. The Schenkels spent five months in the reserve in 1968 following up their 1967 study, described in the last ORYX, September 1968. A second census of the rhinos confirmed their 1967 one, showing between 20 and 29 rhinos in the reserve. On their second visit they found it much easier to get about and see rhinos, thanks to repeated rain even in the dry season, but even so the animals were usually only found in dense vegetation where they were difficult to observe. However, they found one rhino lying in a pool in the river, and were able to photograph it before it got their scent and rushed off into the jungle. The Schenkels were joined for a short time by a young Indonesian plant sociologist, Dr Soeriaadmadja, who began a study of the plant communities to provide data for future management plans which must ensure food for the rhinos. Protection and management of this reserve is vital for the survival of the Javan rhino.

\section{Wild Asses Return to Israel}

IN THE Hay Bar Nature Reserve in Israel there are now three pairs of 1 onager, together with one foal born in the reserve and seen in the photograph opposite. The reserve, in the charge of General Yoffe, was started with the idea of re-introducing animals mentioned in the Bible that have been exterminated in Palestine. The onager, the Persian wild ass, is an endangered subspecies of the wild ass closely allied to the Syrian subspecies, now extinct, that was formerly found in Palestine. The three pairs were brought to Israel with the aid of the World Wildlife Fund, and the Israeli Nature Reserves Authority hopes to build up the herd and eventually to release some in the Negev. The Hay Bar reserve, for which 10,000 acres has been allotted, is in the Arava, 30 miles north of Eilat on the Gulf of Aqaba, and on the road to the Dead Sea. 